\title{
LAS MUJERES CAÍDAS COMO HEREDERAS DE MARÍA MAGDALENA EN EL AUDIOVISUAL (1910-1919)
}

Elena Monzón Pertejo

Universitat de València

Data recepción: 2019-04-23

Data aceptación: 2020-05-15

Contacto autora: elena.monzon@uv.es

ORCID: https://orcid.org/0000-0003-4133-3146

\section{RESUMEN}

En ocasiones, las imágenes actúan como focos de influencia para la creación de otras imágenes, historias o personajes (Fritz Saxl). Este es el caso de la mítica Magdalena, quien ha funcionado como agente contaminante para crear toda una estirpe de herederas, entre las que se encuentran las mujeres caídas. Estos personajes viven su auge en la literatura decimonónica, teniendo también su presencia en la pintura de esa misma cronología. Después, saltarán al cine con un importante incremento en la segunda década del siglo XX. En el presente texto se estudia este fenómeno en el cine norteamericano del periodo que abarca de 1910 a 1919. En este sentido, se abordan dos cuestiones principales: por un lado, la herencia de María Magdalena y los fundamentos teóricos para ello y, por otro, las posibilidades que ofrece la prensa cinematográfica para llevar a cabo la aproximación al significado de películas que no se han conservado.

Palabras clave: mujer caída, María Magdalena, cine, literatura, Fritz Saxl

\section{ABSTRACT}

Images can be a point of influence for the creation of other images, stories or characters. This is true of the mythical Mary Magdalene, a contaminating factor in the creation of a whole line of heiresses, among them fallen women. These characters experienced their apogee in 19th-century literature and art, before making the move to cinema and becoming especially prevalent in the second decade of the 20th century. This paper studies this phenomenon in North American cinema of the period between 1910 and 1919. Two main issues are addressed: the legacy of Mary Magdalene and its theoretical foundations; and the possibilities offered by the film press in gaining an understanding of films that have not survived to this day.

Keywords: fallen woman, Mary Magdalene, cinema, literature, Fritz Saxl

\section{Introducción}

En el periodo del cine silente, de forma paralela a la presencia de María Magdalena en las películas de temática bíblica, hay también toda una serie de producciones con argumentos ajenos a los evangelios cuyas protagonistas son herederas de la Magdalena: las mujeres caídas. Este tipo de personaje ha sido ampliamente estudiado en el terreno de la literatura decimonónica y la pintura finisecular, y cuenta con algunos estudios en el ámbito cinematográfico (Watt 1984; Logan 1998; Andres 2005; Campbell 1974; Jacobs 1997; Campbell 2006). Aunque en todos estos trabajos es común la mención a María Magdalena, por la caída en desgracia de estas mujeres a partir del pecado sexual, existe un vacío a la hora de adentrarse 
en este aspecto más allá de la simple referencia nominal. Por ello, en el presente estudio se hace un análisis de las mujeres caídas atendiendo a la herencia de la mujer de Magdala, proponiendo unas bases teóricas en las que sustentar dicha cuestión y estudiando las posibles variantes de dicha carga.

Esta operación se lleva a cabo a partir de distintas producciones dirigidas por Allan Dwan (1885-1981), D. W. Griffith (1875-1948) y Arthur Hopkins (1878-1950). Este último cineasta no sólo incluye a las mujeres caídas sino también a la antecesora por excelencia como personaje que transita a través de los tiempos. Las obras estudiadas proceden, todas ellas, de los Estados Unidos en el periodo que abarca desde1910 a 1919.' Es éste un marco cronológico en el que las producciones cinematográficas presentan una problemática debido, principalmente, a que muchas de las películas se han perdido, y se conoce de ellas únicamente el título, la fecha, el autor y conservándose, en ocasiones, algún fotograma aislado. Por lo tanto, una problemática común para este periodo del cine reside en la imposibilidad de visualizar parte de los materiales por las situaciones señaladas. Para solventar esta cuestión, y gracias a que, con bastante frecuencia, estas produciones audiovisuales parten de obras literarias precedentes, en el presente estudio se realiza la aproximación al significado de las películas no visualizadas recurriendo a las obras literarias en las que se basan y a la crítica cinematográfica del momento. Todo ello se completa con el recurso a los elementos contextuales así como a los propios de la tradición cultural, tanto de la mujer de Magdala como de estas mujeres caídas y de la propia historia del cine.

\section{Apuntes previos}

Antes de abordar los objetivos planteados, resultan necesarias unas aclaraciones previas. La primera cuestión refiere a la presencia de María Magdalena en el audiovisual. El año 1897 se considera como la fecha en la que el relato evangélico aparece en el medio cinematográfico, con el estreno del film de Léar La pasión de Cristo (Léar, La Passion du Christ, 1897). No obstante, hasta que la casa Pathé realiza La Vida y Pasión de Nuestro Señor Jesucristo (Ferdinand Zecca, La
Vie et Passion de Nostre Seigneur Jésus Christ, 1902-1907), María Magdalena no aparece con identidad propia. La presencia de este personaje se elabora en su faceta de pecadora arrepentida, con un protagonismo que irá en aumento a medida que el cine vaya decantándose por la vertiente narrativa. Como ya se ha apuntado, en el caso que aquí ocupa no serán las producciones de temática bíblica las estudiadas, sino las protagonizadas por las herederas de la mujer de Magdala.

El segundo apunte necesario refiere al grado de herencia de María Magdalena en estos personajes: algunos apelan directamente a su figura; otros recurren a su nombre para generar la asociación de ideas y, por último, están los que simplemente guardan el recuerdo de su tradición por el vínculo con la prostitución y el pecado sexual. ¿Es, entonces, María Magdalena el arquetipo a partir del que se construyen estas mujeres caídas? Con el propósito de alejar el estudio de planteamientos psicoanalíticos, se ha optado por rechazar el término arquetipo por su origen jungiano. Se busca un alejamiento de tal término por su planteamiento atemporal, ahistórico; por su falta de comprensión de los fenómenos en su historicidad, por el vacío en el que son desarollados y explicados dichos arquetipos. Por el contrario, se busca la comprensión de toda construcción cultural en un tiempo y cultura concreta, o, si se trata de un análisis diacrónico, a través de los tiempos y sociedades pero siempre teniendo presente su condición de constructo y no de cuestión innata. Por todo ello, en lugar de arquetipo se ha elegido el término mujer-concepto, bajo el cual se encuadran los conceptos, rasgos, itinerarios, comportamientos... que perfilan a la Magdalena mítica y que contaminan a sus herederas.

Asimismo, como anclaje teórico para el estudio de la carga hereditaria, se recurre a la teoría de Fritz Saxl por la cual las imágenes, aunque creadas en un momento determinado con un significado propio, continúan su vida a lo largo del tiempo convirtiéndose en agentes contaminantes para otras creaciones. A esta potencialidad de las imágenes Saxl la denominó como «poder magnético» (Saxl 1989). Todo ello participa de la línea de pensamiento de Aby Warburg y su teoría de la memoria social donde las imágenes vivirían 
etapas de letargo y etapas de renacer con sus distintas fases de continuidad y variación (Warburg 2005). ${ }^{2}$

La tercera puntualización necesaria se refiere a la consideración de María Magdalena como personaje mítico. Como han demostrado los numerosos estudios procedentes de la teología feminista, la imagen literaria que de María Magdalena se desprende de los evangelios canónicos es distinta a la Magdalena que se ha difundido a través de las manifestaciones culturales de los siglos siguientes (Bernabé 1994; Ricci 1994; Schaberg 2008). Ello se debe a que su figura se deforma a partir de la exégesis realizada por la patrística latina, en el seno de un ideario patriarcal y androcentrista, que minimiza la importancia de la Magdalena del evangelio para convertirla en una pecadora que, tras arrepentirse, alcanza la salvación. Es por ello que aquí se utiliza el término «mítico» para referir, como han hecho otras autoras (Haskins 1996), a ese personaje creado por medio de la simbiosis con otras mujeres del evangelio, con un pasado pecaminoso, una fase de arrepentimiento y conversión y un destino de salvación. ${ }^{3}$

Entre las mujeres que pasan a configurar el híbrido que es la Magdalena se encuentran: la pecadora del Evangelio de Lucas (LC 7, 36-50); la ungidora anónima de Betania (Mc 14, 3-9 y Mt 26, 6-13); María de Betania, hermana de Marta y de Lázaro (Jn 12, 1-9), y la mujer adúltera cuya lapidación evita Jesús (Jn 8, 3-7). Todas ellas, además de las distintas leyendas que se difundieron en los siglos medievales, configuran a la Magdalena mítica que pervive en el siglo XXI: la pecadora sexual que, llorando a los pies de Jesús, pidió perdón por sus pecados y, gracias a la misericordia del nazareno, obtuvo la redención y alcanzó la salvación tras una vida de arrepentimiento y penitencia. En definitiva, el mito de la Magdalena es el de la mujer caída en desgracia por el pecado sexual que, finalmente, y no sin sufrimiento, logra redimirse. Es este itinerario, con sus variantes, el que seguirán las protagonistas de las películas estudiadas.

\section{Las mujeres caídas del Ochocientos}

Desde finales del siglo XII, se fundaron por Europa toda una serie de instituciones destinadas a acoger a las mujeres de la calle, como la iniciada por Rodolfo de Worms en 1225. Gran parte de estas instituciones tenían a María Magdalena como patrona, esa beata peccatrix, castisima meretrix, que debía servir de ejemplo a las mujeres que allí se cobijaban (Haskins 1996, 162 y 201-204). El aumento de la prostitución del siglo XII fue todavía más álgido en el siglo XIX, especialmente en las ciudades inglesas, donde las prostitutas, al motor de la revolución industrial, incrementaban su número y visibilidad en las calles. Así, las instituciones para albergar a las mujeres siguieron aumentando. Es este ambiente el que servirá a gran parte de las obras literarias en las que luego estarán basadas las películas. ${ }^{4}$

El tema de la prostitución no pasó inadvertido para algunos artistas, como por ejemplo Félicien Rops que, bajo títulos como El Rydeack (c.1865), Indigencia (1882) o La bebedora de absenta (1876), presentaba a estas mujeres demacradas esperando la llegada de algún cliente. Edgar Degas (Escena de burdel, 1876-1877) y Toulouse-Lautrec (Salón de la Rue des Moulins, 1894) también dedicaron parte de su obra a esta temática (Bornay 1990). La misma aparece también entre los miembros de la Hermandad Prerrafaelita con obras como Found Drowned de George F. Watts (1848-1850) (fig. 1) o Found de Rossetti (1865-1869). En definitiva, la prostitución fue un fenómeno en auge en la mayoría de las capitales europeas y objeto de interés por parte de diversos artistas finiseculares.

La literatura victoriana fue ampliamente profusa en esta temática, siendo el poema de Thomas Hood The Bridge of Sighs (1844) uno de los referentes principales, junto a novelas como Mary Barton (Gaskell 1848) o No Name (Collins 1862), Armadale (Collins 1866) o The New Magdalen (Collins 1873). Estas obras están protagonizadas por mujeres caídas, prostitutas hambrientas, muchachas traicionadas, o jóvenes sumidas en la desgracia que no pueden librarse de su pasado de prostitución, a pesar de sus intentos por integrarse de nuevo en la sociedad. Estas mujeres sólo podían alcanzar un final verdaderamente feliz si en su vida aparecía un hombre que, bondasoso, piadoso y redentor, les posibilitase esa reintegración que tanto ansiaban. No obstante, a falta de estos salvadores, un final alternativo, y sólo 


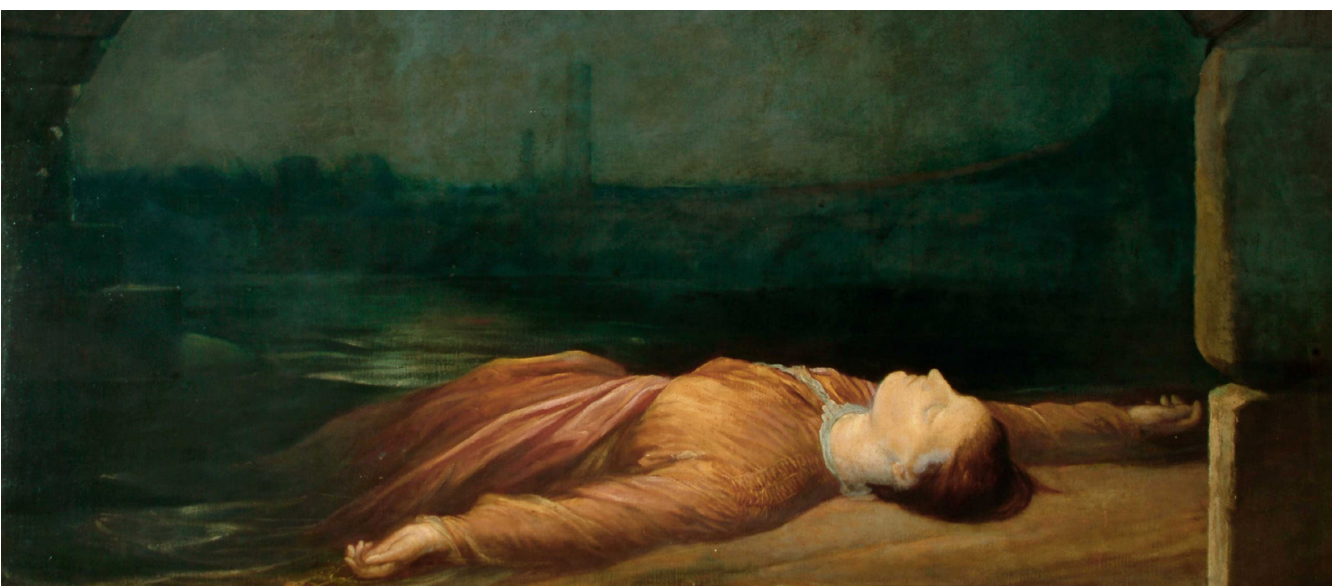

Fig. 1. Watts, George Frederic, Found Drowned, 1850. Óleo (Watts Gallery, Compton)

parcialmente feliz, podía darse por la ayuda de las mujeres caritativas que, siendo ángeles del hogar, salían del espacio doméstico para ayudar a las muchachas de la calle, consideradas por el puritanismo victoriano como sus antítesis (Hapke 1986, 16-22).

Estas madonas caritativas forman parte del fenómeno filantrópico tan en auge en la sociedad victoriana, que además conllevó un importante sesgo de género: la filantropía fue entendida, mayoritariamente, como una actividad femenina, tanto por su extensión del papel de madre como por la supuesta pureza moral que ostentaban los ángeles del hogar. La concepción de las mujeres se articulaba así entre estos dos polos, el ángel del hogar y la prostituta, las madonas y las magdalenas, en donde las primeras lograban salir al espacio público gracias a las segundas. Asimismo, esta actividad abría a las mujeres una vía para hablar de temas relacionados con la sexualidad (Walkowitz 1993). En todos estos textos se encuentran consideraciones de la época sobre las mujeres, como su condición de dependientes del marido o del padre, la polaridad madona-magdalena, lo nocivo de la prostitución y la concepción de los hombres como salvadores que rescatan a las mujeres caídas al igual que Jesús hizo con la mujer de Magdala. Las herederas de la Magdalena se convertían así en mártires de la sociedad, salvadas por las piadosas burguesas (Trudgill 1976). Muchos de estos aspectos aparecen claramente reflejados en varias de las producciones audiovisuales que más adelante se comentan, como por ejemplo el rescate de la joven protagonista por un hombre honesto en Way Down East (G. W. Griffith, 1920) o el personaje de Martha Bradshaw en The Eternal Magdalene (Arthur Hopkins, 1919), caracterizada como el ángel del hogar que sale en rescate de las mujeres caídas.

\section{Herederas de la Magdalena en el audio- visual}

Russell Campbell indica, en su estudio sobre la prostitución en el cine, que las primeras películas con prostitutas eran de carácter cómico y que aparecieron directamente con el nacimiento del cine en 1897 (Campbell 2006, 8-9). Las películas aquí seleccionadas, lejos de tener tintes cómicos, se insertan en el género del melodrama con la mujer caída como joven traicionada y abandonada como denominador común. Es en este tipo de personajes, insertos en relatos dramáticos, en los que se muestran claramente los nexos con la mítica Magdalena por representarse, argumentalmente, el mismo itinerario vital del mítico personaje: protagonistas caídas por el pecado sexual, con una historia de vergüenza, arrepentimiento, y en algunos casos de redención, conllevando así conceptos y comportamientos definitorios de su mítica antecesora.

El primero de estos films, The Way of the World (D. W. Griffith, 1910), dirigido por Griffith y producido por Biograph Company, se estrenaba el 25 
de abril de 1910. ${ }^{5}$ En este melodrama se trata el tema de la joven descarriada, con Florence Barker dando vida al personaje llamado "The Modern Magdalene". En la prensa del momento, una de las críticas se abría con la frase "Aquel que esté libre de pecado que tire la primera piedra», referencia directa al Evangelio de Juan por la tradicional confusión de María Magdalena con la mujer adúltera $(8,3-7)$. Argumentalmente, la reseña apunta a un joven sacerdote en su empeño por recuperar a los feligreses de una comunidad que se ha ido alejando de la religión. La heredera de María Magdalena, una joven caída en desgracia, termina arrodillándose ante el joven sacerdote $y$, pidiendo perdón como su mítica antecesora, promete dedicar el resto de su vida a la penitencia. ${ }^{6}$ Ello concuerda con el tono general del film tal y como se señala en otra de las reseñas de la época: la obra debía mostrar las cuestiones morales de un modo maniqueo al incidir en «el contraste entre la bondad y el pecado».? Las alabanzas a esta producción de Griffith son generalizadas en toda la prensa del momento, siendo bautizada la película como una «lección de caridad cristiana» que se ganó el aplauso de todo el público. ${ }^{8}$ Respecto al personaje interpretado por Florence Barker, se indica que esta "Magdalena de hoy en día» se convierte en la seguidora del joven sacerdote, constituyendo la película un verdadero sermón, un Ilamamiento a la enseñanza cristiana. ${ }^{9}$

En An Innocent Magdalene (Allan Dwan, 1916), Allan Dwan retoma el tema que había tratado dos años antes en su film Remember Mary Magdalene (Allan Dwan, 1914).10 La actriz Lilian Gish, en el papel protagonista de la película de 1916, interpreta de Dorothy Raleigh, una joven de Kentucky que contrae matrimonio con un hombre que, inmerso en el mundo de las apuestas, no es aceptado por su padre, el Coronel Raleigh. Embarazada y abandonada, la joven regresa al hogar paterno donde es repudiada, quedándole como único refugio el barrio de las prostitutas. Allí, en soledad, dará a luz a su hijo (fig. 3) (Lombardi 2013, 30). De nuevo, se actualiza el tema de la Magdalena situándolo en los tiempos modernos, fuera de narraciones bíblicas, para asociar a la criatura mítica con las mujeres caídas, al igual que sucedía en la obra de este mismo director de 1914. Precisamente es la actriz que interpreta a Dorothy, Lillian Gish,

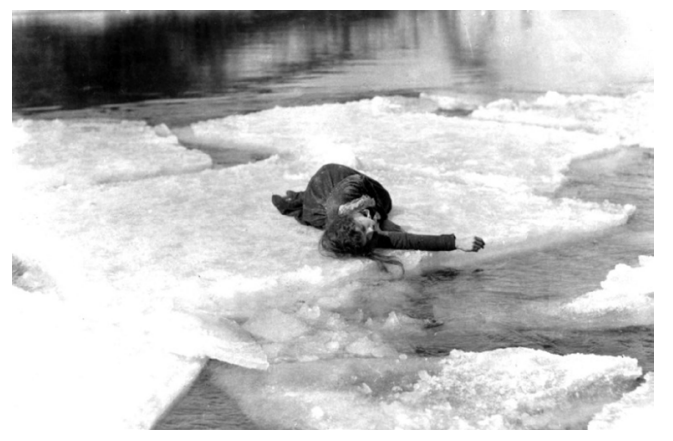

Fig. 2. Dwan, Allan, An Innocent Magdalene, 1916

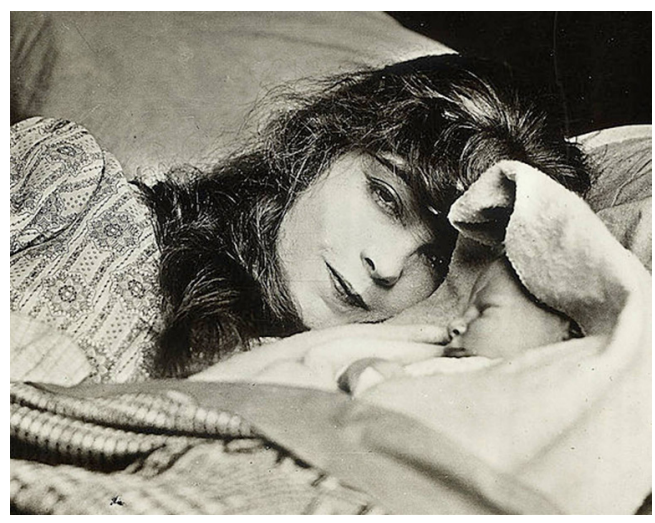

Fig. 3. Griffith, David Wark, Way Down East, 1920

la misma que aparece en la película de D.W. Griffith Intolerancia (Intolerance. Love's Struggle Throughout the Ages, 1916) en el papel de la joven madre. El vínculo entre ambas películas no se limita a la actriz, sino que se amplía al propio D. W. Griffith, ya que éste, bajo el pseudónimo de Granville Warwick, fue uno de los creadores de la historia del film de Allan Dawn. ${ }^{11}$

Griffith retomará este tema en Way Down East (1920) -película que sí se ha conservado- donde Lilian Gish interpreta a Anna Moore, una joven envuelta en un falso matrimonio del que nace un bebé que muere al poco tiempo. El pasado de la joven la perseguirá en sus intentos de reconstruir su vida y, finalmente, acabará en medio de una ventisca derrumbada sobre un río helado a punto de quebrarse. No obstante, a esta heredera de la Magdalena le corresponde el final feliz que se mencionaba al tratar las novelas decimonónicas: es salvada de la muerte por un joven bondadoso y con gran capacidad de perdón que, enamorado 


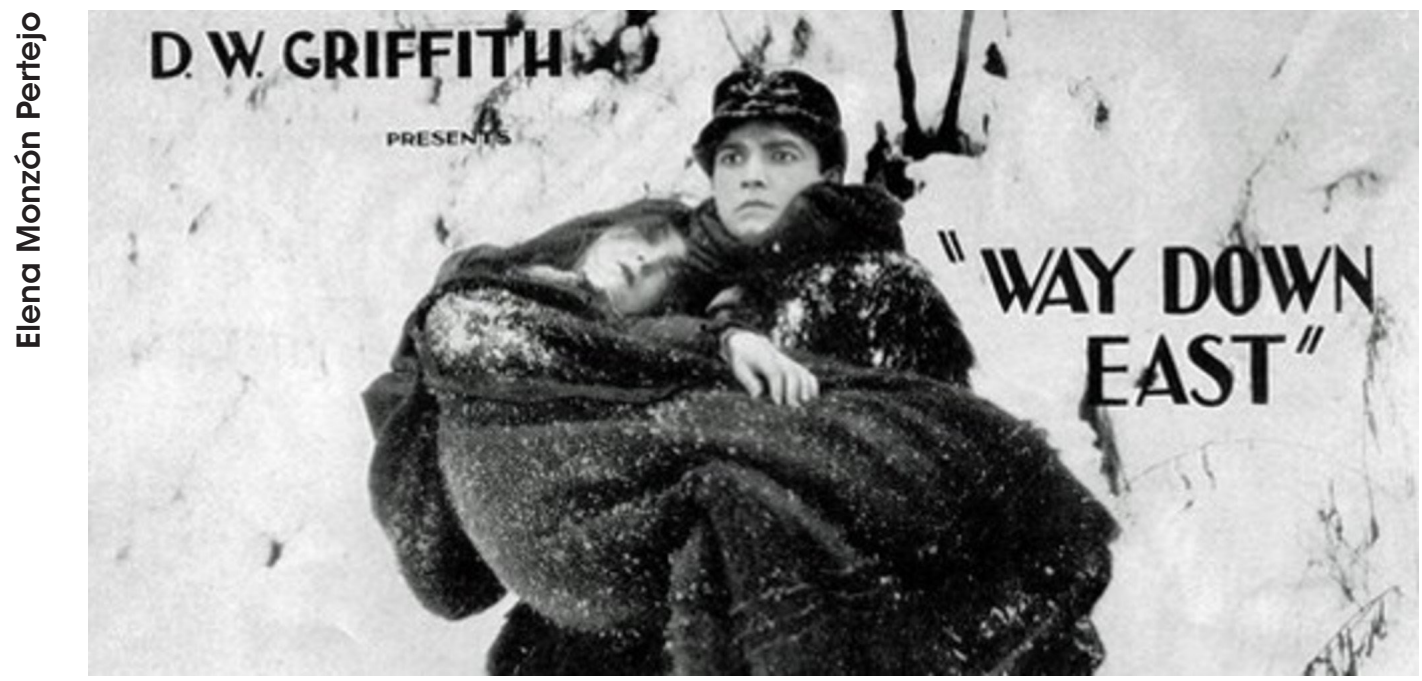

Fig. 4. Griffith, David Wark, Way Down East, 1920

de ella, la rescata en el último momento en una de las escenas más representativas del melodrama silente (figs. 2 y 4). En la prensa especializada del momento, este film es mencionado en numerosas ocasiones incluso antes de su estreno. Ello se debe, en parte, a la gran cantidad de dinero que Griffith desembolsó para comprar los derechos de autor del drama teatral homónimo de William A. Brady. En este sentido, la prensa señala que la suma constituyó «el mayor precio pagado nunca por los derechos de una novela y obra teatral».12 Concretamente, la cantidad emitida por el director ascendía a los $\$ 175.000 .^{13}$

En un artículo escrito por John Emerson y Anita Loos (Emerson y Loos 1921), asiduos colaboradores de la revista Motion Picture Magazine, se detallan los elementos que conforman un drama poniendo ejemplos concretos como la obra de Griffith. De las distintas cuestiones tratadas, destacan el conflicto mostrado entre los códigos morales y las realidades y obstáculos de la vida, como los que sufre la protagonista de Way Down East. Respecto a la temática, estos mismos críticos indican que el centro principal es la moral, «una lección que se trata de dar a la audiencia, o el hecho que se trata de demostrar. En Way Down East de Griffith, se muestra el peligro de la intolerancia moral que no acepta ninguna explicación para la mujer caída» (Emerson y Loos 1921, 60-61). Anna Moore, como mujer caída, termina siendo rescatada por el joven honesto que está enamorado de ella y, de este modo, puede reintegrarse en la sociedad.

\section{Madonas y Magdalenas en The Eternal Magdalene (Arthur Hopkins, 1919)}

Es la producción norteamericana dirigida por Arthur Hopkins, The Eternal Magdalene (1919) -basada en la obra teatral de Robert McLaughlin The Eternal Magdalene. A Modern Play in Three Acts de 1918 (McLaughlin 1918)- la que mejor concentra todos los elementos relacionados no sólo con el tema de las mujeres caídas y María Magdalena sino también con las madonas que salen en su ayuda. Este film sufrió retrasos en su estreno debido a la censura y al igual que en otras de las producciones, no ha sido posible el acceso a su visionado. Sin embargo, una vez más, gracias a la crítica cinematográfica y la obra literaria que adapta, es posible aproximarse a los principales ejes que se verían reflejados en el film.

Situada la acción en la localidad de Fort Hill en 1917, el argumento gira en torno a la respetable familia Bradshaw, donde el padre, Mr. Bradshaw, encabeza el comité ciudadano que pretende expulsar a las prostitutas de la localidad, cuestión ésta que articula toda la obra. La trama avanza por medio de la transformación de Mr. Bradshaw, desde una postura de radical 
rechazo e intolerancia hacia las prostitutas a una actitud de tolerancia y comprensión. Todo ello se orquesta con la repentina aparición de una misteriosa mujer, momento a partir del que toda una serie de desgracias se ciernen sobre la familia del protagonista: se descubre que su hijo ha robado dinero, su hija se escapa de la ciudad con un hombre casado que termina abandonándola y la esposa de Mr. Bradshaw, Martha, fallece a causa de los disgustos. La misteriosa mujer es María Magdalena, personaje que recibió de Jesús la misión de viajar a través del tiempo para ayudar a las que han caído en el pecado. Bess, la hija de Mr. Bradshaw, representa a las jóvenes traicionadas que acaban en la calle, y su madre a las piadosas burguesas entregadas a las actividades filantrópicas, especialmente a la ayuda de las prostitutas.

La obra presenta distintas actitudes respecto a la prostitución: Mr. Bradshaw y su rechazo inicial a lo que considera la mayor depravación y vergüenza, una auténtica plaga que «debe ser erradicada a cualquier precio» (McLaughlin 1918, 4-5); Martha, la esposa del protagonista, representa la postura contraria al socorrer a estas mujeres, escuchando sus historias y comprendiendo sus situaciones. Este hecho conlleva cierto conflicto en el matrimonio, al rechazar Mr. Bradshaw la ayuda que su mujer presta a esas mujeres que «han perdido todo el derecho a la simpatía humana». Aunque Mr. Bradshaw admite que la pobreza puede ser una de las causas de la prostitución, ésta no deja de ser «consecuencia de la pereza» $\mathrm{y}$ «el amor traicionado es un apodo para la lujuria» (McLaughlin 1918, 30).

El personaje de María Magdalena tiene presencia incluso antes de la aparición de la actriz que la interpreta, siendo mencionada por primera vez a raíz del cuadro colocado en la biblioteca de la familia Bradshaw, en donde aparece representada junto a Jesús. En su primera aparición física, la mujer indica su condición de mujer de la calle, cuestión reforzada por su aspecto: vestida de rojo, con un traje extremadamente corto, y con multitud de baratijas que adornan su cuerpo. Una vez cumplida su misión de concienciar a Mr. Bradshaw sobre la situación de las prostitutas, la Magdalena explica que su objetivo consistía en hacerle ver su «incapacidad para juzgar a tus semejantes» y para demostrarle que «la desgracia no siempre viene por nuestros actos». La mujer se define a sí misma como «la Magdalena eterna, hecha inmortal por el toque de Su mano hace dos mil años», en referencia directa a la adúltera que es salvada de la lapidación: «Cuando aquéllos querían apedrearme, el Salvador se levantó diciendo: 'Tampoco yo te condeno'». En ese momento, Jesús nombra a la Magdalena como su mensajera: "Ve a lo largo de los siglos y da testimonio de lo que has visto. En todas partes hallarás a los que han pecado como tú has pecado. Párate ante ellos y sus perseguidores como yo lo he hecho». De este modo, María Magdalena se convierte en defensora de los pecadores: "Así he llegado a través de las épocas trasmitiendo sus palabras y seguiré mientras las naciones se derrumban y caen los imperios, llevando su mensaje de misericordia para el hombre». Explicada su historia y misión, la mujer se despide de Mr. Bradshaw: "Mi tarea aquí ha terminado y el Maestro me hace señas desde lejos» (McLaughlin 1918, 86-87).

Al final de la obra literaria, el autor incluye una caracterización de cada uno de los personajes. Para la mujer de Magdala apunta que es aquélla que Jesús salvó de morir lapidada, momento a partir del que dedicó su vida a defender «a las mujeres de la clase a la que ella perteneció», convirtiéndose en «un Ministro de la Misericordia» (McLaughlin 1918, 93-94). Gracias a la crítica cinematográfica del momento, se puede decir que, en sus líneas principales, el film sigue a la obra en la que se basa: un "atrevido drama» que muestra las distintas facetas y aspectos de la vida, como «la belleza, la pasión, la virtud, el pecado, la caridad y la misericordia», y los posibles caminos a los que pueden dirigir. Asimismo, se alaba la labor tanto del director Arthur Hopkins, quien logra crear un "gran cuadro alegórico», como la de Maxime Elliot, la actriz encargada de interpretar a María Magdalena de quien se señala que aprovecha «al máximo su oportunidad en el papel estelar».14

\section{Algunas conclusiones y varios interrogantes}

Como se avanzaba líneas atrás, el trabajo con este tipo de materiales conlleva una tarea específica de "reconstrucción" que es posible, al menos 
en cuestiones de argumento y personajes, con el recurso a la crítica cinematográfica de la prensa del momento, así como a las obras literarias en las que están basadas los films. Se trata de una labor compleja que conlleva peligros derivados del hecho de no contar con el material completo en todas las ocasiones. No obstante, como si de una labor arqueológica se tratara y gracias a elementos clave del contexto, recursos propios de la tradición así como a las fuentes disponibles, ha sido posible la aproximación al significado de unas obras de las que se tenía una presencia parcial e, incluso, una ausencia total del celuloide.

Todas estas películas tratan, de un modo u otro, el tema o el estigma de la prostitución y de las mujeres que han sido arrojadas fuera de la sociedad como consecuencia de establecer una relación-sexual-con un hombre que finalmente las traiciona, engañándolas y abandonándolas, en muchos casos estando embarazadas $y$, por tanto, convirtiéndose en madres solteras. La asociación con María Magdalena se establece ya sea por adjudicarles el mismo nombre, por la referencia a la figura mítica o por el itinerario que estos personajes viven del pecado a la redención, revelándose en todas las vertientes el poder magnético del que hablaba Fritz Saxl. Con ello se demuestra uno de los objetivos planteados al inicio: el poder magnético del mito de la Magdalena para influenciar la creación de personajes que, aunque insertos en narrativas alejadas de los relatos bíblicos, quedan pobladas con sus herederas. Así se ha visto en muchos de estos films, donde las protagonistas se configuran a partir de la herencia del personaje mítico, de esa mujerconcepto que deja toda su carga en esos nuevos personajes contaminados, principalmente, por el aspecto del pecado sexual. La Magdalena mítica es, al mismo tiempo, antecesora y ejemplo de conducta para unos personajes que, en los márgenes de la sociedad, buscan la redención. Igualmente, queda también demostrada la continuidad de temas procedentes de la literatura y pintura decimonónica.

Por lo tanto, María Magdalena es origen, es referente y es elemento contaminante para la creación de toda una estirpe de herederas, de las que aquí se han estudiado únicamente unas pocas. Se trata de un periodo en el que son nu- merosas las películas con este tipo de temas, por lo que surge la cuestión del porqué de este interés por las mujeres caídas en esta cronología. La respuesta a dicha cuestión podría configurar un estudio por sí mismo, por lo que en las próximas líneas únicamente se apuntan tentativas de respuesta que al tiempo que requerrirían de un estudio en profundidad, dan cierre -provisionala este texto.

En primer lugar, resulta necesario recurrir a la historia del cine para ofrecer una posible respuesta. La fase del cine de atracciones, predominante hasta 1906-1908, dio paso a la fase narrativa en la que se abandonaba la fascinación por los efectos especiales para centrar la atención en el desarrollo de las historias y los personajes, siendo el melodrama un género fundamental en este sentido. Es precisamente en fechas paralelas a este cambio cuando se produce el auge de María Magdalena en las películas de temática bíblica, así como en las protagonizadas por sus herederas. Por lo tanto, una posible causa residiría en el vínculo entre el desarrollo de historias -dramáticas mayoritariamente- con el gran material existente en la tradición de las mujeres caídas para alimentar estas tramas, unido a las altas posibilidades de éxito que ofrecía su fama en el plano literario.

Por otra parte, no puede ser obviada la importancia de las imágenes como modelos de conducta para el público. Al igual que el arte contrarreformista, el audivoisual también se ha utilizado con fines moralizantes, como demuestran algunas de las críticas de la época incluídas en páginas previas. En las imágenes tridentinas, María Magdalena funcionaba como ejemplo de redención para los pecadores, función que continúan sus herederas en las producciones cinematográficas de inicios del siglo XX. A dicha función se une también la tarea de alertar a las jóvenes de los peligros que entraña la sexualidad. Igualmente, desde su construcción como personaje mítico, la Magdalena ofrece la posibilidad de satisfacer intereses contrarios: al tiempo que se convierte en ejemplo de conducta por su conversión, es también utilizada como coartada para incluir elementos eróticos y temáticas sexuales procedentes de su vida de pecadora. Este uso de la santidad -no sólo en el caso de María Magdale- 
na, sino también de otras mujeres bíblicas- como velo para mostrar el cuerpo femenino desnudo, o para tratar aspectos relacionados con el sexo, tiene sus antecedentes en pinturas barrocas y su continuidad en lienzos del Ochocientos, en los que la santa penitente expone su voluptuosidad y exuberancia en contextos que resultan difíciles de encajar dentro del arte religioso. ${ }^{15}$ Por lo tanto, otra posible respuesta, no excluyente, se ofrece al interrogante planteado: María Magdalena es utilizada para hablar de un tema, la sexualidad, que resultaba difícil tratar sin una coartada aceptada y asentada en la tradición.

En definitiva, la poliédrica Magdalena es un mito capaz de adaptarse a las diversas etapas, estilos y formatos, viviendo periodos de auge y sirviendo como modelo a partir del cual crear toda una familia de herederas. El cine de los primeros tiempos utilizó a estos personajes en su afán por desarrollar historias en un modelo cinematográfico en el que triunfó la narratividad. 


\section{NOTAS}

1 Aunque en la presente investigación se ha limitado geográficamente a los Estados Unidos, en otros países surgían también producciones de esta temática. En Alemania, por ejemplo, el director Hans Oberländer y el productor Oskar Messter realizan el film Maria Magdalena, donde se presenta la historia de una pecadora en la ciudad de Berlín en vísperas a la Gran Guerra; en Rusia, Viatchslav Tourjanski estrenaba otra obra con el mismo título. También en Reino Unido surgen este tipo de temas, como es el caso de la película dirigida por Walter West The Answer (1916), basada en la novela de Walter Newman Flower Is God Dead? (Flower 1915) donde uno de los personajes, interpretado por Dora Barton, recibe el nombre de "Lost Magdalen". Igualmente, el director austriaco Otto Kreisler estrena en 1919 su película Maria Magdalena, basada en la obra homónima de Friedrich Hebbel (Hebbel 1844)

2 Para un estudio global del pensamiento de Warburg así como de sus discípulos véase Rafael García Mahíques, Iconografía e Iconología. Volumen 1. La Historia del Arte como Historia Cultural (Madrid: Encuentro, 2008).

3 A partir de la homilía de Gregorio Magno pronunciada en el año 591, se oficializa la fusión de personajes en la figura de María Magdalena: «Hanc vero quam Lucas peccatricem mulierem, Joannes Mariam nominat, illam ese Mariam credimus de qua Marcus septem daemonia, nisi universa vitia designatur? Quia enim septem diebus omne tempus comprehenditur, recte septenario numero universitas figuratur. Septem ergo daemonia Maria habuit, quae universis vitiis plena fuit. Sed ecce quia turpitudinis suae maculas aspexit, lavanda ad fontem misericordiae cucurrit, convivantes non erubuit. Nam quia semetipsam graviter erubescebat intus nihil ese credidit quod verecundaretur foris». Gregorio Magno, Homilia XXXIII, Lectio S. Evang. Sec. Luc. VII, 36-50; PL LXXVI, 1239.

4 Para el vínculo entre María Magdalena y las mujeres caídas de la literatura decimonónica en lengua alemana, véase Ingrid Maisch, Between Contempt and Veneration. Mary Magdalene. The Image of a Woman through the Centuries (Collegeville: The Liturgical Press, 1998), 111-133.

${ }^{5}$ Moving Picture World, JanuaryJune, 1910: 704.

${ }^{6}$ Moving Picture World, JanuaryJune, 1910: 698. La vida de penitente de María Magdalena procede de diversas leyendas que se fueron expandiendo desde el siglo IX y que, en el siglo XIII, fueron recogidas por Santiago de la Vorágine en la Leyenda Dorada. Dicha obra señala que: "Santa María Magdalena, deseosa de entregarse plenamente a la contemplación de las cosas divinas, se retiró a un desierto austerísimo, se alojó en una celda previamente preparada para ella por los ángeles y en dicha celda vivió durante treinta años totalmente apartada del mundo y aislada del resto de la gente" (Vorágine 2001, 382).
7 Moving Picture World, JanuaryJune, 1910: 725.

8 Ibid., 737-738.

9 Ibid., 737-738.

10 Este cortometraje, catalogado como perdido, contaba en su reparto con Pauline Buch, Murdock MacQuarrie y Lond Chaney. El argumento gira en torno al incidente en el que se ve envuelto un hombre por defender a una mujer de la calle. La película ha sido localizada en los listados de la revista Motography, enero-junio 1914, vol. XI, $n^{\circ} 5$, p. 184 y 743, dentro de la sección de melodramas. A pesar de la poca información de la que se dispone, el argumento y el título de la película ofrecen indicios que evidencian la herencia de la Magdalena mítica en la mujer caída que aparece en esta cinta.

${ }^{11}$ Stuart Oderman sugiere que Griffith planteó la temática de la mujer embarazada y abandonada como prueba para ver la reacción del público y, en función de la respuesta de los espectadores, utilizarla posteriormente en Way Down East (Oderman 2000, 64).

${ }^{12}$ Motion Picture Magazine, February-July, 1920: 84.

${ }^{13}$ lbid., 129.

${ }^{14}$ Current Opinion, v. 63, 1917: 252.

15 En este sentido, ejemplos paradigmáticos son las obras de Guido Reni (Magdalena penitente, siglo XVI) y de Jules Joseph Lefèbvre (María Magdalena en la cueva, 1876). 


\section{REFERENCIAS}

Andres, Sophia. The pre-Raphaelite Art of the Victorian Novel. Narrative Challenges to Visual Gendered Boundaries. Columbus: The Ohio State University Press, 2005.

Bernabé, Carmen. María Magdalena. Tradiciones en el cristianismo primitivo. Estella: Verbo Divino, 1994.

Bornay, Erika. Las hijas de Lilith. Madrid: Cátedra, 1990.

Campbell, Marilyn. The Fallen Woman in Hollywood Films, 1931-1933. Madison: University of Wisconsin-Madison, 1974.

Campbell, Russell. Marked Women: Prostitutes and Prostitution in the Cinema. Madison: University of Wisconsin Press, 2006.

Collins, William W. Armadale. Leipzig: Bernhard Tauchnitz, 1863.

Collins, William W. No Name. Leipzig: Bernhard Tauchnitz, 1863.

Collins, William W. The New Magdalen. Leipzig: Bernhard Tauchnitz, 1863.

Emerson, John y Loos, Anita. "What Makes a Photograma." Motion Picture Magazine (February-July, 1921): 60-61.

Jacobs, Lea. The Wages of Sin: Censorship and the Fallen Woman Film, 1928-1942. Berkeley - Los Angeles: University of California Press, 1997.

Logan, Deborah A. Fallenness in Victorian Women's Writing: Marry, Stitch, Die, or Do Worse. Columbia - London: University of Missouri Press, 1998.

Flower, Newman W. Is God Dead? Londres: Casell, 1915.

García Mahíques, Rafael. Iconografía e Iconología. Volumen 1. La Historia del Arte como Historia Cultural. Madrid: Encuentro, 2008.

Gaskell, Elizabeth. Mary Barton. A Tale of Manchester Life. London: Chapman \& Hall, 1848.

Hapke, Laura. "He Stoops to Conquer: Redeeming the Fallen Woman in the Fiction of Dic- kens, Gaskell and Their Contemporaries." Victorian Newsletter 69 (1986): 16-22.

Haskins, Susan. María Magdalena. Mito y metáfora. Barcelona: Herder, 1996.

Hebbel, Friedrich. Maria Magdalene. Einbürgerliches Trauerspiel in drei Akten. Hamburg: Hoffmann und Campe, 1844.

Lombardi, Frederic. Allan Dwan and the Rise and Decline of the Hollywood Studios. JeffersonLondon: McFarland, 2013.

McLaughlin, Robert. The Eternal Magdalene. A Modern Play in Three Acts. New York: S. French, 1918.

Maisch, Ingrid. Between Contempt and Veneration. Mary Magdalene. The Image of a Woman through the Centuries. Collegeville: The Liturgical Press, 1998.

Oderman, Stuart. Lillian Gish: A Life on Stage and Screen. Jefferson: McFarland, 2000.

Ricci, Carla. Mary Magdalene and Many Others. Women who Followed Jesus. Minneapolis: Fortress Press, 1994.

Saxl, Fritz. La vida de las imágenes. Estudios iconográficos sobre el arte occidental. Madrid: Alianza, 1989.

Schaberg, Jane. La resurrección de María Magdalena. Leyendas, apócrifos y testamento cristiano. Estella: Verbo Divino, 2008.

Trudgill, Eric. Madonnas and Magdalens: The Origins and Development of Victorian Sexual Attitudes. London: Heinemann, 1976.

Vorágine, Santiago. La Leyenda Dorada, 1. Madrid: Alianza, 2001.

Walkowitz, Judith. "Sexualidades peligrosas." En Historia de las mujeres. El siglo XIX. Vol. 4, editado por Georges Duby y Michelle Perrot, 389-426. Madrid: Taurus, 1993.

Warburg, Aby. El renacimiento del paganismo. Aportaciones a la historia cultural del Renacimiento europeo. Madrid: Alianza, 2005.

Watt, George. The Fallen Woman in the Nineteenth-Century English Novel. London - New York: Routledge, 1984. 
